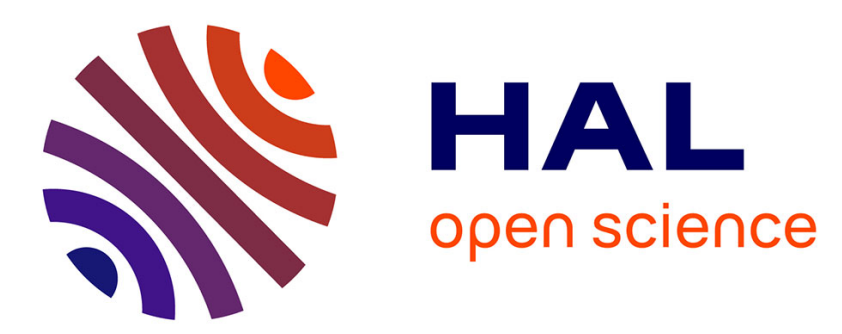

\title{
Preparation and Properties of Asymmetric Synthetic Membranes based on Lipid and Polymer Self-Assembly
}

Ariane Peyret, Hang Zhao, Sébastien Lecommandoux

\section{To cite this version:}

Ariane Peyret, Hang Zhao, Sébastien Lecommandoux. Preparation and Properties of Asymmetric Synthetic Membranes based on Lipid and Polymer Self-Assembly. Langmuir, 2018, 34 (11), pp.33763385. 10.1021/acs.langmuir.7b04233 . hal-01722205

\section{HAL Id: hal-01722205 https://hal.science/hal-01722205}

Submitted on 8 Jul 2019

HAL is a multi-disciplinary open access archive for the deposit and dissemination of scientific research documents, whether they are published or not. The documents may come from teaching and research institutions in France or abroad, or from public or private research centers.
L'archive ouverte pluridisciplinaire HAL, est destinée au dépôt et à la diffusion de documents scientifiques de niveau recherche, publiés ou non, émanant des établissements d'enseignement et de recherche français ou étrangers, des laboratoires publics ou privés. 


\title{
Preparation and Properties of Asymmetric
}

\section{Synthetic Membranes based on Lipid and Polymer}

\section{Self-Assembly}

Ariane Peyret, Hang Zhao, Sébastien Lecommandoux*

Laboratoire de Chimie des Polymères Organiques, LCPO, Université de Bordeaux, CNRS, Bordeaux INP, UMR 5629, 16 Avenue Pey Berland F-33600 Pessac, France.

* correspondance to : S. Lecommandoux (lecommandoux@enscbp.fr)

KEYWORDS: membrane, asymmetry, biomimicry, lipid, polymer

\begin{abstract}
Cell membrane asymmetry is a common structural feature of all biological cells. Researchers have tried for decades to better study its formation and its function in membraneregulated phenomena. Especially, there has been increasing interest in developing synthetic asymmetric membrane models in the laboratory, with the aim of studying basic physicalchemistry properties that may be correlated to relevant biological function. The present article aims at summarizing the main presented approaches to prepare asymmetric membranes, which are most often made from lipids, polymers, or a combination of both.
\end{abstract}




\section{INTRODUCTION}

1972 was a milestone in research biology when the famous fluid mosaic model was proposed as an interpretation of biological membrane structure by Singer and Nicolson (Figure 1). ${ }^{1}$ Biological membranes were defined as " $[\ldots]$ analogous to a two-dimensional oriented solution of integral proteins (or lipoproteins) in the viscous phospholipid bilayer solvent." This model provided a solid base to start explaining membrane organization ("mosaic") and predicted many membrane phenomena regulated by lipid and protein dynamic rearrangement ("fluid").

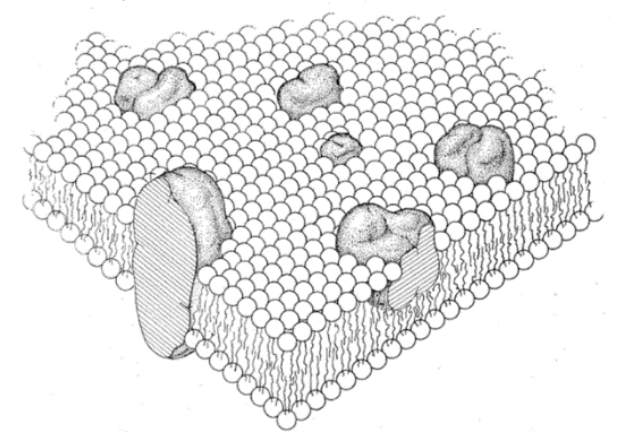

Figure 1. Schematic three-dimensional representation of the fluid mosaic structure of the membrane, reproduced with permission from Ref. [1]. Copyright [1972] \{Science]. Globular proteins inserted into a lipid matrix.

Around that same period of time, Bretscher introduced the concept of "asymmetry" to characterize membrane structure through the different repartition of lipids and proteins across the two leaflets of the bilayer. ${ }^{2-3}$ One of his five guidelines for membrane structure was that the basis of a biological membrane is a bilayer enriched with choline lipid derivatives and glycolipids in the exoplasmic side and amino-phospholipids in the cytoplasmic side. ${ }^{3}$ In 1974 , a breakthrough in understanding of biomembrane, the bilayer couple hypothesis, was 
proposed by Sheetz and Singer. They hypothesized that the existed asymmetry feature within a bilayer would result in the two leaflets may respond independently and differently to a perturbation while maintaining coupled to one another, which underpin the mechanism of functional consequences, such as shape changes in a cell. ${ }^{4}$ Evidence of asymmetry was already supported with several examples involving selective binding of substrates to one side or the other or phospholipase digestion. ${ }^{5-7}$ For example, ferritin was shown to specifically bind to oligosaccharides with $d$-mannose or $d$-glucose residues on the outer surface of erythrocyte membranes and not on the inner cytoplasmic surface. ${ }^{8}$

While proteins were also shown to be unevenly organized between both leaflets, asymmetry in biological membranes mostly comes from the distribution of lipids, which play a major structural and functional role. Indeed, their amphiphilicity allows them to spontaneously form membranes in the form of small compartments to segregate internal constituents from the external medium. They also act as messengers in signal transduction and molecular recognition processes and they are used for energy storage. ${ }^{9}$ It is now well-established that the differences in constituents between both sides of the bilayer have a strong impact on membrane physical properties such as permeability, membrane curvature (linked to the intrinsic asymmetric nature of lipids), shape or surface charge (negatively-charged phospholipids on the cytoplasmic side). ${ }^{10-13}$ Consequently, disruption of the normal membrane asymmetry often has significant physiological consequences such as blood coagulation or recognition and removal of apoptotic cells by macrophages. ${ }^{14-16}$ For example, phosphatidylserine exposure on the outer leaflet is a sign for cell apoptosis. ${ }^{17-20}$ These processes are essential for cell development but if unregulated, they could be the source of pathologic conditions. ${ }^{21}$ Asymmetry of lipid charge has shown impact on determination of transmembrane protein oridentation, ${ }^{22}$ and a recent study proved that the segments of transmembrane contains smaller side chains prefer to exist in the outer monolayer of bilayer. ${ }^{23}$ 
Thus, maintaining the repartition of constituents and mainly lipids between the two leaflets and hence maintaining asymmetry, is crucial for the proper functioning of membrane regulated cellular phenomena. ${ }^{9,14,24}$ As such, a lot of energy is invested by the cell to maintain the non-random distribution of species across the bilayer with the help of transporter enzymes such as flippases (ATP-dependent) or floppases (ATP independent) which are in charge of controlling the transmembrane distribution of lipids. ${ }^{21,25-30}$

The study of biological membranes has been facilitated by the preparation of synthetic symmetric lipid membranes either supported or in the form of vesicular systems. ${ }^{31-32}$ Models with asymmetric membranes would however be more realistic in cell structural biomimicry studies but they have been difficult to establish experimentally mostly because of a lack of reliable methods to precisely control and quantify the asymmetry. Still, over the last few years, significant progress has been made in the preparation of such model systems using mostly lipid-only membranes. ${ }^{33}$ There are however many other possibilities to form asymmetric membranes with cell mimicking properties by using alternative synthetic pathways or constituents such as polymers or peptides. ${ }^{32}$ The goal of this review is to gather and summarize the main cell mimicking asymmetric membrane models that have been proposed and studied over the last years. We aim at providing a non-exhaustive review of the different systems with respect to geometry and composition, focusing on the most relevant synthetic routes.

We firstly describe the main different methodologies to prepare asymmetric membranes made exclusively from lipids. We then outline innovative approaches that have been presented with polymers and finally give an overview of a few systems that combine both lipids and polymers. These systems are schematically illustrated in Figure 2, which presents the main preparation routes, compositions and morphologies that have been reported for asymmetric lipid and polymer membranes. 


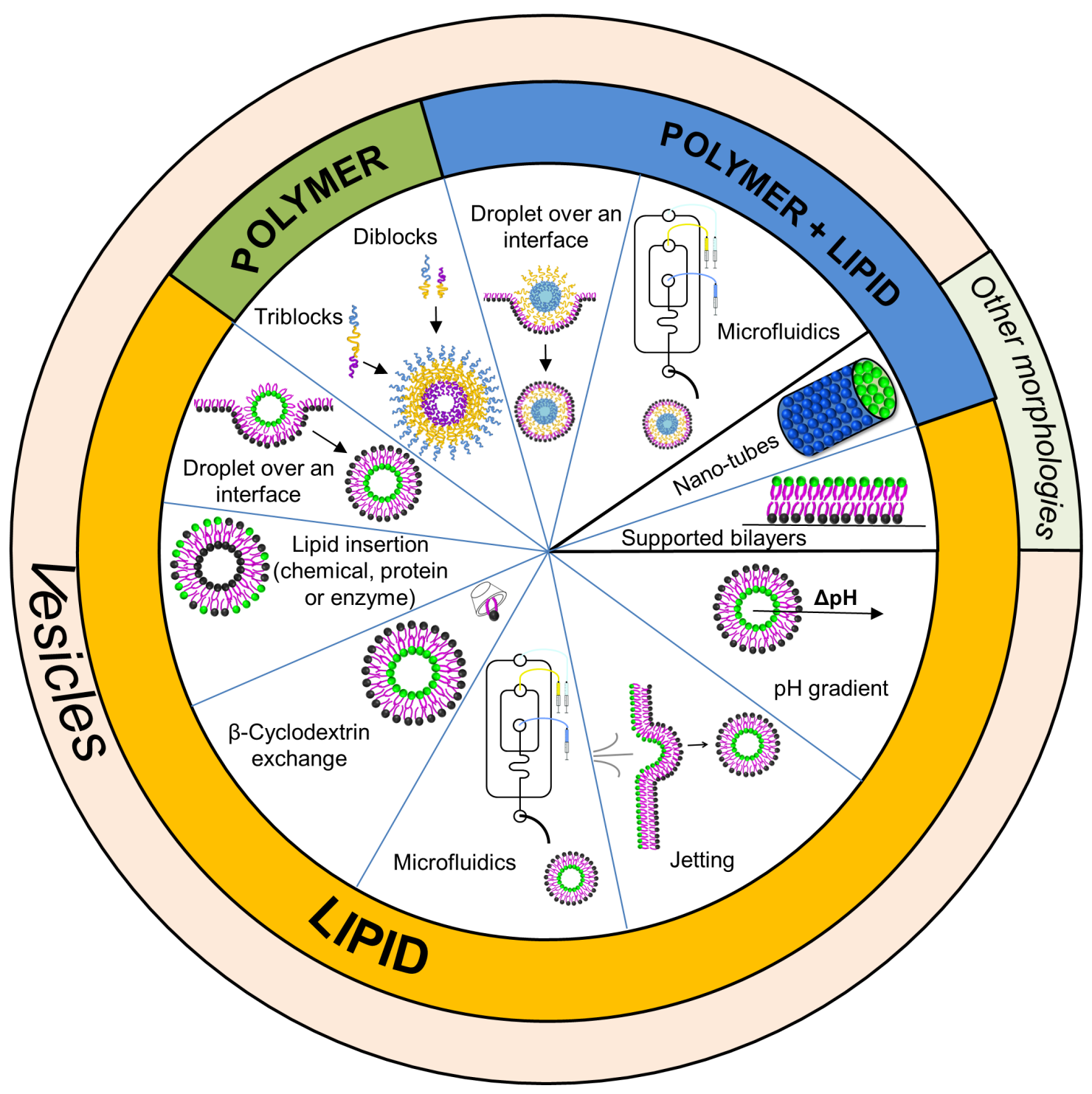

Figure 2. Schematic representation of some of the reported strategies to prepare synthetic asymmetric membranes with respect to composition and morphology, including $\mathrm{pH}$ gradient, ${ }^{34}$ lipid insertion by proteins / enzymes or chemicals, ${ }^{35-37} \beta$-cyclodextrin, ${ }^{38-40}$ droplet over an interface, ${ }^{41-44}$ jetting, ${ }^{45}$ supported bilayers, ${ }^{46}$ nano-tubes, ${ }^{47-48}$ triblock polymers, ${ }^{49-51}$ and microfluidics. $^{52-55}$ 


\section{DESIGN OF ASYMMETRIC MEMBRANES BASED ON LIPIDS}

Lipids are the main constituents of all biological membranes. ${ }^{9,26}$ Their amphiphilic character is responsible for their spontaneous organization into two leaflets that together form a bilayer. Their polar headgroup is oriented towards the external aqueous environment while their hydrophobic tail (hydrocarbon chains) form the core of the membrane. Lipid-only asymmetric synthetic bilayer systems have been widely used and have proven to be highly successful models to study membrane properties. ${ }^{33,56}$ The wide available pool of lipids makes them suitable candidates to form different geometries through various processes detailed below.

Early examples of synthesized asymmetry in small and large vesicles relied on lipid transfer techniques involving lipid exchange proteins or enzymes. ${ }^{35-37,57}$ Lipid transfer proteins were discovered in 1975 in the group of Zilversmit after investigating how lipid components from plasma lipoproteins were taken up by liver cells. ${ }^{35-36}$ Several groups studied the translocation rate of lipids from one monolayer to the other using the lipid exchange or conversion technique essentially by means of NMR after exposing small lipid vesicles to an exchange protein or often to a phospholipase enzyme that converts phosphatidylcholine (POPC) to phosphatidic acid (PA). ${ }^{37,}$ 58-59 The lipid translocation (or flip-flop) rates varied from minutes to a few days depending on the system. ${ }^{37,58}$ Other examples of generating transmembrane bilayer asymmetry involve spontaneous transfer of a lipid from a donor to an acceptor lipid vesicle when the two populations are in close contact or a chemical control with a sodium ascorbate induced extinction of paramagnetism of spin-labelled lipids in the outer monolayer of lipid vesicles. ${ }^{59-60}$

Later on, the $\mathrm{pH}$ gradient technique was proposed by Cullis and coworkers to induce transverse asymmetry in lipid bilayers. ${ }^{34}$ They showed that they could influence the positioning 
of weak acid lipids such as phosphatidylglycerol (PG) by applying a transmembrane $\mathrm{pH}$ gradient in lipid vesicles (inside basic and outside acidic or the reverse). Charged lipids are known to move very slowly from one monolayer to the other but it was expected that using protonated (uncharged) PG lipids would facilitate the movement. It was found that when POPC vesicles with a fraction of PG were prepared with a transmembrane $\mathrm{pH}$ gradient (inside basic), almost 90 $\%$ of PG located in the inner monolayer. Interestingly, the reverse $\mathrm{pH}$ gradient led to the opposite asymmetry and the same vesicles formed with zwitterionic lipids only retained a symmetric distribution of lipids thus confirming the influence of $\mathrm{pH}$ on the movement of weak acid lipids. ${ }^{34}$

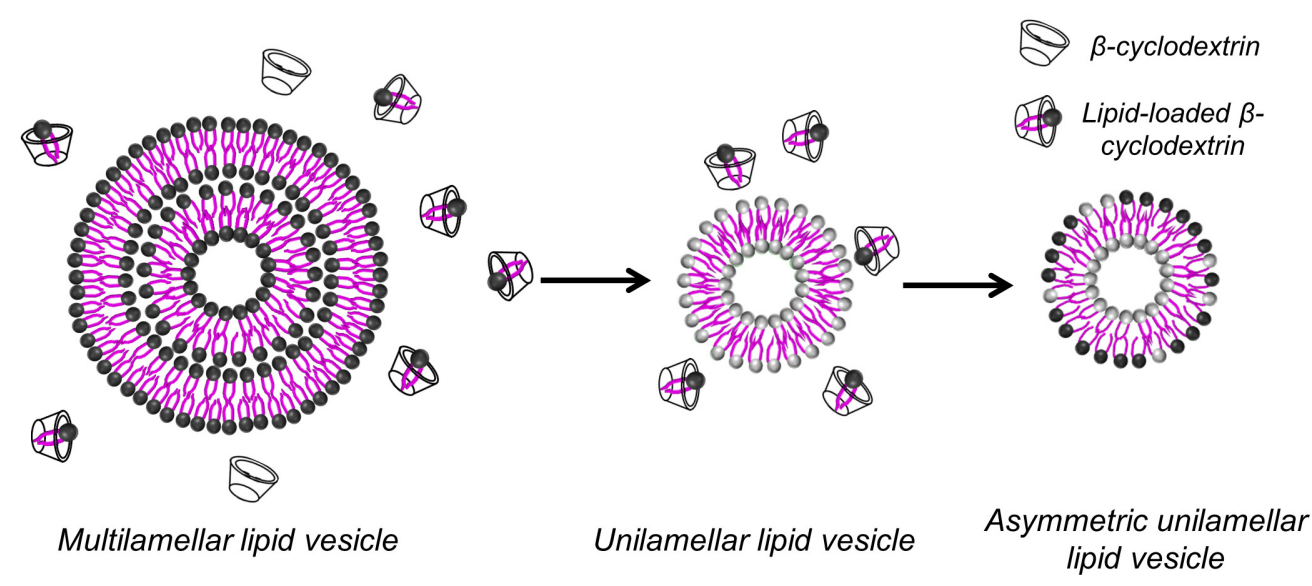

Figure 3. Schematic representation of methyl- $\beta$-cyclodextrin $(\mathrm{M} \beta \mathrm{CD})$ mediated lipid exchange to form asymmetric unilamellar lipid vesicles. Multilamellar lipid vesicles are incubated with $\beta$ cyclodextrin to form lipid- M $\beta C D$ complexes. Unilamellar lipid vesicles are then incubated with an excess of the complexes to generate the asymmetric vesicles.

Strategies based on the ability of cyclodextrin (CD) derivatives to bind and exchange phospholipids have been developed in the laboratory of E. London in the last decade to construct vesicles comprising an asymmetrical distribution of lipids between the lipidic monolayers. ${ }^{61-62}$ 
Methyl- $\beta$-cyclodextrin $(\mathrm{M} \beta \mathrm{CD}$ ) molecules have the ability to bind hydrophobic species within their cavity and thus have attracted much attention as potential carriers for cholesterol, lipophilic drugs or other molecules with low solubility. ${ }^{63}$ In one of their initial studies, sphingomyelin (SM) multi-lamellar vesicles (MLVs) were obtained by rehydration of a dried lipid film. The assemblies were then incubated with highly concentrated M $\beta C D$ to form SM-M $\beta C D$ complexes which were purified and incubated with pre-formed small unilamellar lipid vesicles (SUVs) to allow insertion of SM in the outer lipid monolayer (Figure 3). ${ }^{61}$ High performance thin layer chromatography confirmed a rapid (within minutes) exchange of about $80 \%$ lipid with the outer monolayer of the SUVs whereas control samples with SUVs incubated with SM in the absence of $\mathrm{M} \beta \mathrm{CD}$ only showed traces of exchanged SM. Fluorescence anisotropy measurements of fluorescent probes added to the vesicles were used to confirm asymmetry which was stable over a few days. The authors also showed that cholesterol could be inserted into these asymmetric SUVs by performing a second successive M $\beta C D$ exchange step, confirming the versatility of the process. Following studies by the same group introduced the production of asymmetric large and giant unilamellar vesicles (respectively LUVs and GUVs) through the same M $\beta C D$-mediated lipid exchange with the aim of studying how asymmetry impacts ordered domain formation and inter-leaflet coupling in cell bilayer membranes. ${ }^{38-40,62}$ The advantages of this method are essentially that it requires minimal equipment and that different lipids can be exchanged by this process, proving the flexibility of the method. The versatility in terms of vesicle size (SUVs, LUVs and GUVs) that can be used is also an important aspect as sometimes, methods to yield asymmetric vesicles are restricted/more efficient with a certain vesicle size (either giant or small/large). However, multiple steps (incubation, centrifugation, purification, etc.) are needed to yield the asymmetric vesicles making this method relatively tedious. 
Over the last decade, there has been a growing interest in the development of new synthetic routes with higher control and precision to produce synthetic asymmetric lipid vesicles. Several groups reported on innovative protocols to generate membrane asymmetry with a special focus on giant vesicles (GUVs) that are thought to constitute more adequate cell mimics in terms of membrane physical properties, but they also have as a main strength facile manipulation and observation, as compared with small vesicles, which allows researchers to dig deeper into membrane physical properties. ${ }^{41-43,45,64-65}$

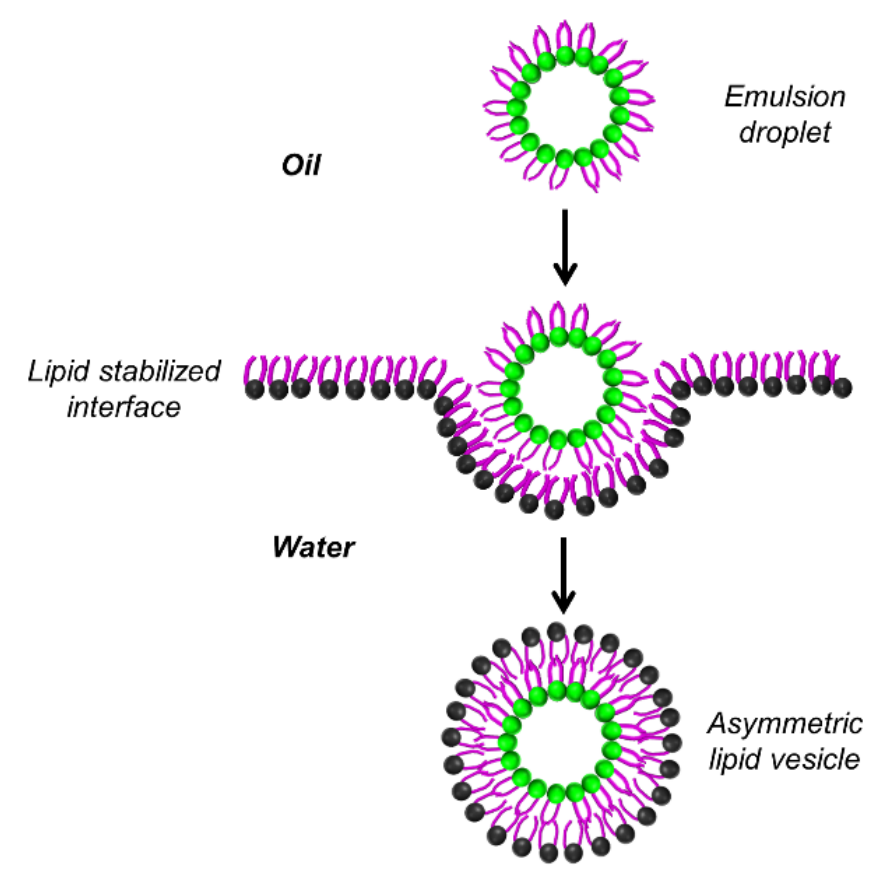

Figure 4. Schematic representation of the "droplet over an interface" method to generate asymmetric lipid vesicles. An aqueous droplet stabilized by a lipid is poured over a different lipid-stabilized oil-water interface.

Rather than through membrane exchange, giant asymmetric lipid vesicles can be assembled by emulsion methods where lipid-stabilized aqueous droplets are forced through a lipid-stabilized 
oil-water interface to generate the bilayer membrane. This process is referred as "droplet over an interface" or "emulsion-centrifugation" method (Figure 4). ${ }^{65-66}$ Weitz and coworkers proposed this method to prepare LUVs (about $500 \mathrm{~nm}$ in diameter) with an inner leaflet of POPC and outer leaflet of phosphatidylserine (POPS), or the reverse. Centrifugation was used to help the lipidstabilized aqueous droplets to cross the lipid-stabilized oil/water interface. One should note that the preparation of asymmetric SUVs was also previously demonstrated by a similar protocol. ${ }^{67}$ The membrane asymmetry of the vesicles and its stability over time were demonstrated with a fluorescence quenching assay. This layer-by-layer assembly allowed insertion of a fluorescentlytagged lipid in one of the bilayer leaflets (POPC monolayer or POPS monolayer) and the fluorescence was measured before and after addition of a fluorescence quencher on the outer medium. For example, when the dye was inserted in the lipid-stabilized interface (outer leaflet of the vesicle membrane), about $95 \%$ fluorescence was lost upon addition of the quencher to the vesicle solution, indicating an almost total asymmetry (no flip from the outer to the inner monolayer). Overall, authors demonstrated that highly asymmetric structures could be obtained using this method, with varying amphiphile molecules (they also performed a test with a lipidpolymer asymmetric membrane). A few years later, the group of Takagi followed a similar procedure to prepare cell-sized (GUVs) asymmetric vesicles with the aim of facilitating manipulation of "biological" vesicles under a controlled environment. ${ }^{41}$ Rather than through centrifugation, the authors used a sugar density gradient to induce spontaneous transfer of the denser lipid-stabilized sucrose droplets through an oil-glucose interface, a strategy that significantly increased vesicle yield. ${ }^{41}$ Other improvements of the "droplet over an interface" or “emulsion-centrifugation" methods involved microfluidics as an efficient way to produce sizecontrolled monodisperse emulsion droplets. ${ }^{43}$ In addition, the continuous droplet interface 
crossing encapsulation (cDICE) method has been described as an efficient way to produce giant vesicles with high throughput production of size-tunable monodisperse vesicles. ${ }^{68-69}$ Vesicles are formed through continuous dripping of droplets off a capillary while forcing their passage through an interface using a centrifugal force. The authors presented the use of the cDICE method to form giant asymmetric vesicles.

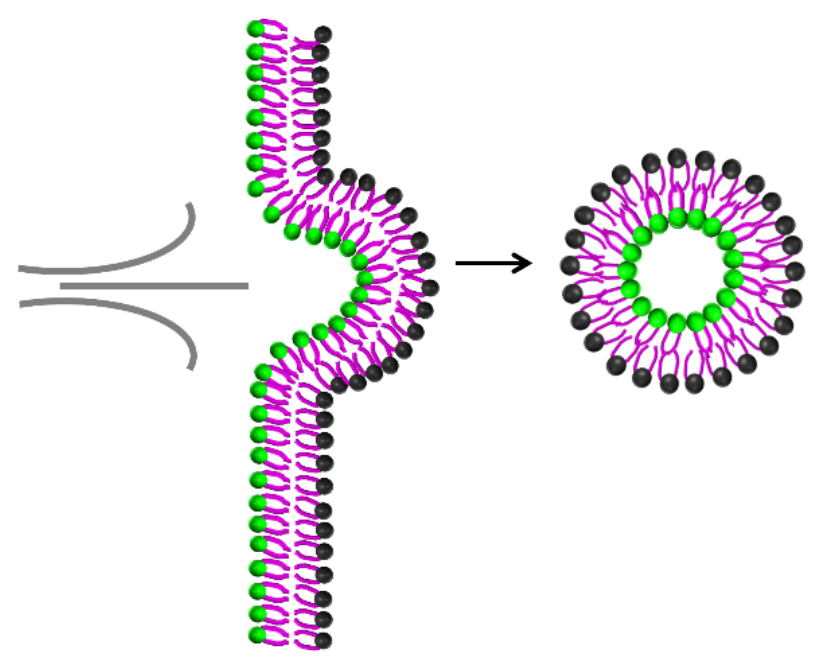

Figure 5. Schematic representation of «jetting ». A jet flow is applied on a lipid asymmetric bilayer where its deformation leads to the formation of asymmetric lipid vesicles.

Advances in microfluidic strategies have led to generating monodisperse emulsion droplets at high-throughput. ${ }^{70}$ Recent developments have enabled emulsions (w/o single emulsions or w/o/w double emulsions) to be used as templates to assemble vesicular structure via a bilayer selfassembly at interfaces, which provides opportunities to control over the composition in the membranes. ${ }^{71}$ Asymmetric membranes constructed based on single emulsions by step-by-step coating with amphiphiles of interested were demonstrated in several group. ${ }^{52-54}$ A water in oil droplet was formed as precursor stabilizing with one kind of lipid molecules, and incubated in 
the channel of microfluidic device, and then coated with the second lipid phase. Recently Zhao et al. has reported that asymmetric bilayer vesicles (asymmetric lipid bilayer or lipid-polymer asymmetric bilayer) can be constructed by dewetting of thin-shell double emulsion templates which were fabricated in a single capillary microfluidic device. ${ }^{55}$ The asymmetry property achieved by aforementioned microfluidic approaches was validated by both confocal laser scanning microscopy and fluorescence quenching assay indicating high degree of asymmetry can be readily produced by microfluidic technologies.

Finally, uncommon original techniques have been presented to construct lipid vesicles comprising an asymmetric membrane. Especially, microfluidic jetting has been introduced. ${ }^{42,45,}$ ${ }^{72-73}$ The main concept is that a jet flow is used to deform a lipid bilayer and induce formation of vesicles (Figure 5). Kamiya and coworkers formed cell-sized asymmetric 1,2-dioleoyl-snglycero-3-phosphocholine (DOPC) / 1,2-dioleoyl-sn-glycero-3-phospho-L-serine (DOPS) vesicles using this technique by induced break up of a phospholipid microtube formed by applying a jet flow on a lipid planar bilayer. ${ }^{45}$ They demonstrated that upon deformation of the lipid bilayer with an applied jet flow, the microtube breakdowns in two distinct vesicle populations of respectively $100-200 \mu \mathrm{m}$ and 3-20 $\mu \mathrm{m}$ in diameter. With this method, authors were able to produce monodisperse asymmetric vesicles with little residual solvent in the membrane to investigate lipid flip-flop. They also examined the amount of residual organic solvent using confocal Raman scattering microscopy, which showed that the cell-sized vesicles accommodated tiny amount of the solvent that hardly produced a layer between the two leaflets. In addition, in vitro membrane protein synthesis was demonstrated, proving the biological relevance of the system. 
Another approach resides in focusing on the membrane alone in the form of a supported lipid bilayer, instead of designing objects which require a precise control over the final shape and which might complicate membrane study. In particular, supported lipid bilayers have been broadly studied and used as membrane models. ${ }^{74}$ They consist of a lipid bilayer either fixed or freely deposited on a solid surface (e.g. gold or mica) and are classically formed by the Langmuir-Blodgett technique (transfer of successive lipid monolayers) or by vesicle fusion (liposomes deposited and allowed to fuse on the surface). ${ }^{75}$ In a recent study, dioleoylphosphatidylcholine (DOPC) supported bilayers were formed by vesicle fusion and $\mathrm{M} \beta \mathrm{CD}$ was used to enrich the upper DOPC leaflet with sphingomyelin (SM) thus generating an asymmetric bilayer which stayed stable for up to a few hours, before SM started flipping to the lower leaflet. ${ }^{46}$ While this approach does not allow a precise control over the degree of asymmetry it is however tunable, easy to handle and solvent-free, making it suitable to reconstruct synthetic asymmetric membranes. Similar studies showed the formation of asymmetric domains in supported bilayers. ${ }^{76-77}$

Overall, important advances have been made in the field of asymmetric membrane models, especially in the last decade, using lipidic systems. The different proposed technologies to construct lipid-based membrane asymmetry allowed gaining more control into the design of synthetic membranes. In addition, these approaches have considerably helped the investigation and understanding of lipid dynamics in biological membranes.

\section{DESIGN OF ASYMMETRIC MEMBRANES BASED ON BLOCK COPOLYMERS}


When considering the design of biological membrane mimics, lipids come as an obvious choice for a starting material. However, cellular membranes are only made with about $60 \%$ of lipids and are actually much more complex than pure lipidic bilayers. ${ }^{78}$ Indeed, proteins, glycoproteins, glycolipids, glycans or cholesterol that are incorporated in cell membranes convey precise mechanical properties that cannot be effectively represented by lipid-only membrane models. ${ }^{33}$ More recently, new synthetic asymmetric membranes have been proposed, with other constituting materials and morphologies, with the shared goal of determining to what extent asymmetry influences membrane properties.

A promising approach in the field of cellular membrane mimics resides in the use of polymers. Because of their synthetic nature which makes them chemically stable and tunable, polymers have attracted a lot of attention for the bottom-up assembly of cell mimics, especially in the form of polymer vesicles, or polymersomes, which possess tougher and thicker membranes than their lipid analogues. ${ }^{79-85}$ Such unique properties have been advantageously used to design complex systems, ranging from compartmentalized vesicles to mixed systems. ${ }^{80,86-94}$ As such, Zhang and coworkers presented a phase-guided assembly technique to form giant polymersomes from two amphiphilic diblock copolymers: poly(ethylene oxide)- $b$-poly( $\varepsilon$-caprolactone) (PEO- $b$-PCL) and dextran- $b$-poly( $\varepsilon$-caprolactone) (DEX- $b$-PCL) ${ }^{95}$ The vesicles self-assembled from an aqueous two-phase system, where PEO formed the continuous phase and dextran the dispersed phase. Phase separation led DEX- $b$-PCL to align at the surface of the dextran droplets (with dextran facing the interior) and PEG- $b$-PCL to form the outer leaflet of the bilayer, with PEG facing the continuous phase. The asymmetry of the GUVs was confirmed by means of NMR and fluorescence experiments. The authors also demonstrated the possibility to encapsulate 
erythropoietin with high loading efficiency (ascribed to the thermodynamically favored partition) and a well-preserved bioactivity, thus demonstrating the biological relevance of their system.

A majority of investigated copolymers have an $\mathrm{AB}$ structure, where $\mathrm{A}$ is hydrophilic and $\mathrm{B}$ is hydrophobic, which self-assemble into symmetric membranes. However, ABC triblock copolymers (A and C water soluble but chemically different blocks and B hydrophobic middle block) were recently introduced to form polymersomes bearing an asymmetric membrane upon film rehydration. ${ }^{49-51,96-97}$ When using such polymers, three different conformations can be obtained following vesicle formation: A block on the inside and C on the outside, the reverse, or a mixture of $\mathrm{A}$ and $\mathrm{C}$ on either side (symmetric). Due to their intrinsic asymmetric nature, if the orientation of the triblocks can be controlled or influenced inside the membrane, it is thus possible to present total asymmetry. For example, designing triblocks with different molecular weights for the $\mathrm{A}$ and $\mathrm{C}$ blocks should result in the longer one segregating on the outside of the vesicle due to a larger radius of curvature (differing volume fraction) and the smaller one segregating on the inside ${ }^{51,98}$ Furthermore, by adopting in the same fashion, Eisenberg et al. has expanded chemical localization of distinct groups facing to the interior or exterior aqueous environment, which was utilized to form polymeric vesicles with compositional asymmetric bilayers built by preferentially segregation of diblock copolymer molecules. ${ }^{99}$ Recently, Tordarson has demonstrated that a family of synthesized diblock copolymers featured with different hydrophilic moieties can be used to generate polymersomes with asymmetric membrane to mimic the asymmetry across cell membranes. Interestingly, triblock copolymers have the same block ratios as the mixture of diblock copolymers extensively produced micelles rather than vesicular archetectures might due to the short hydrophobic block, which was evidenced by cryo-TEM. ${ }^{49}$ Using charged blocks is another technique to help block segregation 
on either side of the membrane as has been shown by Zhong and coworkers who formed biodegradable chimaeric polymersomes from poly(ethylene oxide)- $b$-poly(caprolactone)- $b$ poly(2-(diethylamino) ethyl metacrylate) (PEO- $b$-PCL- $b$-PDEA) triblock copolymers with an outer PEO block and inner PDEA charged block assumed to facilitate efficient protein encapsulation and stabilization. ${ }^{97}$ Others have used cleavable peptide-linked triblock copolymers to form vesicles with asymmetric membranes that can undergo shape transformation into multicavity vesicles upon cleavage. ${ }^{100}$

While vesicles with asymmetric membranes formed from polymers are still in an early research stage, they hold promise in the design of new synthetic cellular analogues and have great potential for biomedical applications.

\section{MEMBRANE ASYMMETRY IN HYBRID LIPID-POLYMER SYSTEMS}

Mixing lipids and polymers to form synthetic asymmetric membranes has been rarely exploited but has a lot of potential interest. Indeed, combining the advantages of lipids as an intrinsic cell component and the chemical versatility of polymers may provide a powerful and versatile way to prepare original membranes with the ability to mimic the physical properties of cells. To date, such combination has only been used to develop so-called hybrid membranes that can be engineered to be homogeneous or heterogeneous (phase separation) in composition. ${ }^{101-109}$

In this context, our group has recently reported the preparation of giant vesicles comprising an asymmetric polymer/lipid membrane using the "droplet over an interface" protocol (emulsioncentrifugation process that has been optimized for both polymers and lipids). ${ }^{44,}{ }^{110-111}$ As schematically represented in Figure 6, a polymer stabilized emulsion droplet is poured over an oil-water lipid stabilized interface and, with help of centrifugation, the resulting vesicles are recovered in the lower water phase. As a result, the generated giant vesicles possess an 
asymmetric membrane composed of an outer lipid (POPC) monolayer and inner polymer (PBut$b$-PEO) layer. We also showed that the reverse asymmetric vesicles could be formed, with the lipid facing the inside of the vesicle and polymer facing the outer medium. Complete membrane asymmetry was demonstrated with fluorescence quenching assays and membrane properties were determined by evaluating lipid lateral and transverse diffusion coefficients.

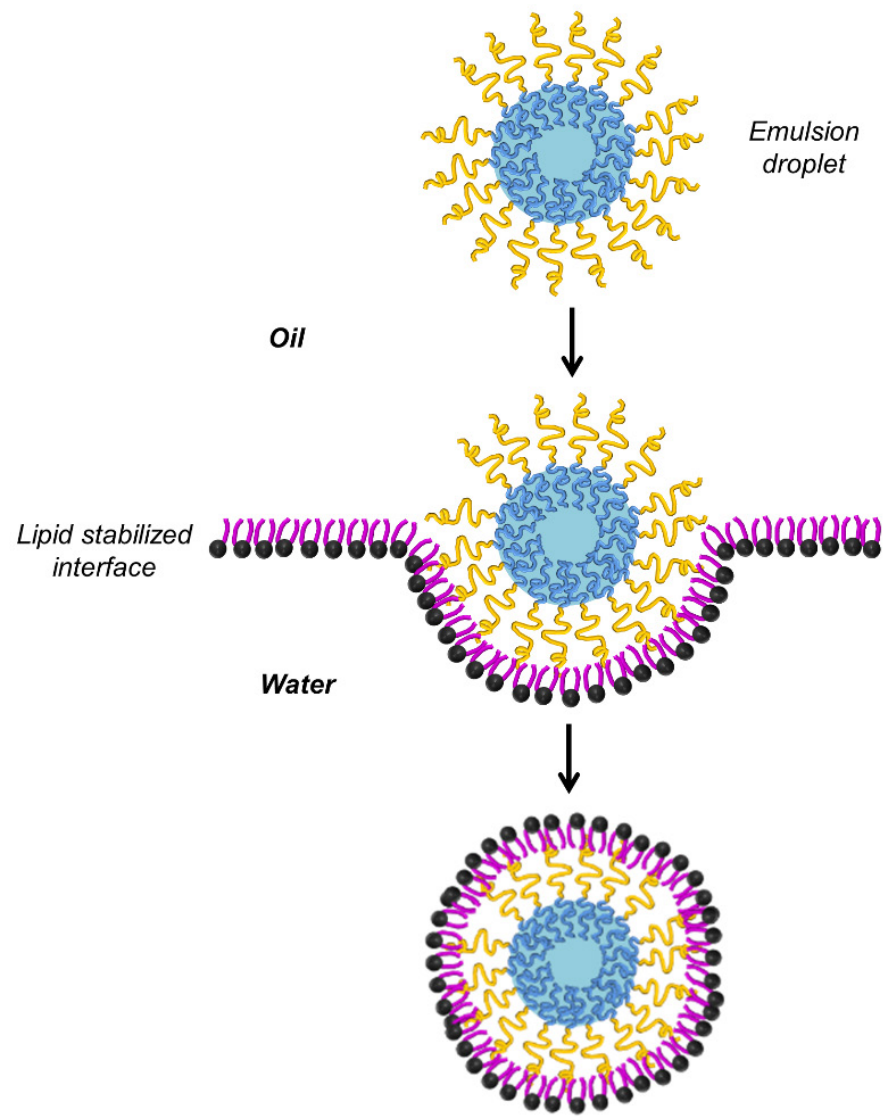

Figure 6. Schematic representation of the "droplet over an interface" method to generate asymmetric lipid-polymer vesicles. ${ }^{44}$ An aqueous droplet stabilized by a polymer is poured over a lipid-stabilized oil-water interface. ${ }^{110}$

Although vesicles appear as an optimal choice in the field of cell biomimicry, alternative morphologies comprising asymmetric membranes have also been investigated. In particular, 
tubular structures have been presented. ${ }^{47-48,112}$ As illustrated by Liedberg and co-authors, an equimolar proportion of poly(butadiene)- $b$-poly(ethylene oxide) and POPC led to the formation of nano-tubular vesicles. They also demonstrated that asymmetry generates a net spontaneous curvature, with the lipid segregating into the inner compressed leaflet, that is required for the stabilization of the tubular morphology. ${ }^{48}$ Finally, amphiphilic peptides were also interestingly considered in generating spontaneous membrane asymmetry in nanotubes or nanoribbons. ${ }^{47,112}$ Amphiphilic peptides based constructs show promising potential as building blocks for the assembly of membrane with compositional asymmetric arrangement. Taking their advantages of being rationally designed for specific bio-macromolecular targets and being highly biocompatible as well as easy degradation in the in vivo environment enable new class of peptide-based biomembranes to open the new avenues to assemble the asymmetric membranes in the form of intracellular delivery vehicles, personalized medicine carriers and ultra-sensitive biosensors.

\section{EFFECTS AND APPLICATIONS OF ASYMMETRIC BILAYER SYSTEMS}

Biological membrane systems possess some degree of lipid asymmetry with respect to bilayer composition prepared by methods as reviewed above have been studied on physical properties of asymmetric biomembranes and membrane-mediated cellular process. Microfluidic-assisted approaches enable well-controlled construction of asymmetric lipid bilayer vesicles at high throughput fashion. ${ }^{54,113}$ The effects of tailored lipid bilayer on the mechanical property has been determined by the fluctuation analysis technique and micropipette aspiration system. In both works, the bending modulus of synthetic asymmetric vesicles were at $30 \%$ higher than the values of acquired for symmetric bilayer vesicles. The implication of the findings on the effects 
of transbilayer asymmetry on mechanical property could pave the way for investigating proteinlipid interaction, especially the mechanosensitive channel whose integration into membrane is controlled by membrane asymmetry. ${ }^{114}$ Asymmetric biomembranes were utilized as a promising models to govern the orientation of membrane proteins during incorporating into synthetic biomembranes. ${ }^{115-116}$ Meier group reported that triblock copolymer built asymmetric membranes can induce a favor insertion orientation of Aquaporin 0 which remain functional inside polymeric membranes. Oiki et al. successfully demonstrated that oriented reconstitution of a potassium channel (KcsA) driven by where the preferred lipid deposits within the asymmetric bilayer. A recent study was undertaken by Chen revealing a transbilayer asymmetry induced translocation of $\beta$-galactosidase. ${ }^{117}$ To address issue of random incorporation of membrane proteins using asymmetric biological membranes would not to broaden knowledge of interactions between membrane proteins and biomembranes, but also propose a versatile way to produce highly functional bio-device.

\section{CONCLUSION}

Over the last years, reconstitution of model membrane systems has helped researchers gain better understanding into the complex machinery of cellular processes, from simple diffusion through membranes to incorporation of transmenbrane proteins or lipid dynamics and clustering. Asymmetric biomembranes are more accurate mimicking systems to resemble natural cell membranes than the unsymmetrical membrane systems. The construction of asymmetric synthetic membranes through a variety of different methods and components open new opportunities to dig deeper into our understanding on the cell machinery and could lead to the development of new therapeutic approaches where lipids should play a major role. Besides as to artificially build a cell upon lifeless components, bioinspired vesicles featured with asymmetric 
bilayer are a step forward to the resemblance of cells in terms of function and structure of biological membranes. The proposed systems so far are very simple and mimic in a very simplistic manner some of the basic properties of cell asymmetry and not at all the biological phenomenon beyond this.

Future work will focus on designing new strategies are desirable to reach stable artificial asymmetric membranes with high control, precision and biological resemblance, from both structural and functional view-points. Eventually, these systems might find interest to better elucidate the significance of lipid asymmetric distribution in cell membranes and uncover how asymmetry is initially formed and maintained as well as assist to gain insight in cellular functions associated with membrane asymmetry.

\section{ACKNOWLEDGEMENT}

This work was funded by the French Ministry of Research and Education (fellow A.P.) and the Agence Nationale de la Recherche (ANR program NO-SynthCell N8 ANR-14- CE16-0015). CPER CampusB project funded by the French state and the Région Nouvelle Aquitaine is also acknowledged.

\section{AUTHOR INFORMATION}

\section{Corresponding Author}

* Tel: +33 5400022 41. Fax: +33 5400084 87. E-mail: lecommandoux@enscbp.fr

\section{Author Contributions}


The manuscript was written through contributions of all authors. All authors have given approval to the final version of the manuscript.

\section{ABBREVIATIONS}

cDICE, continuous droplet interface crossing encapsulation; CD, cyclodextrin; DEX- $b$-PCL, dextran-b-poly(e-caprolactone); DOPC, 1,2-dioleoyl-sn-glycero-3-phosphocholine; DOPS, 1,2dioleoyl-sn-glycero-3-phospho-L-serine; GUVs, giant unilamellar vesicles; LUVs, large unilamellar vesicles; M $3 C D$, methyl- $\beta$-cyclodextrin; MLVs, multi-lamellar vesicles; PA, phosphatidic acid; POPC, phosphatidylcholine; PG, phosphatidylglycerol; POPS, phosphatidylserine; PEO- $b$-PCL, poly(ethylene oxide)- $b$-poly( $\varepsilon$-caprolactone); PEO- $b$-PCL- $b$ PDEA, poly(ethylene oxide)- $b$-poly(caprolactone)- $b$-poly(2-(diethylamino) ethyl metacrylate); SM, sphingomyelin; SUVs, small unilamellar vesicles. 


\section{REFERENCES}

1. Singer, S. J.; Nicolson, G. L., The Fluid Mosaic Model of the Structure of Cell Membranes. Science 1972, 175 (4023), 720-731.

2. Bretscher, M. S., Membrane structure: some general principles. Science 1973, 181 (4100), 622-629.

3. Bretscher, M. S., Asymmetrical Lipid Bilayer Structure for Biological Membranes. Nature 1972, 236 (61), 11-12.

4. Sheetz, M. P.; Singer, S., Biological membranes as bilayer couples. A molecular mechanism of drug-erythrocyte interactions. Proceedings of the National Academy of Sciences 1974, 71 (11), 4457-4461.

5. Verkleij, A. J.; Zwaal, R. F. A.; Roelofsen, B.; Comfurius, P.; Kastelijn, D.; van Deenen, L. L. M., The asymmetric distribution of phospholipids in the human red cell membrane. A combined study using phospholipases and freeze-etch electron microscopy. Biochimica et Biophysica Acta (BBA) - Biomembranes 1973, 323 (2), 178-193.

6. Zwaal, R. F.; Roelofsen, B.; Colley, C. M., Localization of red cell membrane constituents. Biochim. Biophys. Acta 1973, 300 (2), 159-182.

7. Steck, T. L.; Dawson, G., Topographical Distribution of Complex Carbohydrates in the Erythrocyte Membrane. Journal of Biological Chemistry 1974, 249 (7), 2135-2142.

8. Nicolson, G. L.; Singer, S. J., Ferritin-Conjugated Plant Agglutinins as Specific Saccharide Stains for Electron Microscopy: Application to Saccharides Bound to Cell Membranes. Proceedings of the National Academy of Sciences 1971, 68 (5), 942-945.

9. van Meer, G.; Voelker, D. R.; Feigenson, G. W., Membrane lipids: where they are and how they behave. Nat Rev Mol Cell Biol 2008, 9 (2), 112-124.

10. Rothman, J. E.; Lenard, J., Membrane asymmetry. Science 1977, 195 (4280), 743-753.

11. Lodish, H.; Berk, A.; Zipursky, S. L.; Matsudaira, P.; Baltimore, D.; Darnell, J., Biomembranes: Structural Organization and Basic Functions. 2000.

12. Manno, S.; Takakuwa, Y.; Mohandas, N., Identification of a functional role for lipid asymmetry in biological membranes: Phosphatidylserine-skeletal protein interactions modulate membrane stability. Proceedings of the National Academy of Sciences of the United States of America 2002, 99 (4), 1943-1948.

13. Devaux, P. F., Static and dynamic lipid asymmetry in cell membranes. Biochemistry 1991, 30 (5), 1163-1173.

14. Fadeel, B.; Xue, D., The ins and outs of phospholipid asymmetry in the plasma membrane: roles in health and disease. Critical reviews in biochemistry and molecular biology 2009, 44 (5), 264-277.

15. Lentz, B. R., Exposure of platelet membrane phosphatidylserine regulates blood coagulation. Progress in Lipid Research 2003, 42 (5), 423-438.

16. Zwaal, R. F. A.; Schroit, A. J., Pathophysiologic Implications of Membrane Phospholipid Asymmetry in Blood Cells. Blood 1997, 89 (4), 1121-1132.

17. Fadok, V. A.; Voelker, D. R.; Campbell, P. A.; Cohen, J. J.; Bratton, D. L.; Henson, P. M., Exposure of phosphatidylserine on the surface of apoptotic lymphocytes triggers specific recognition and removal by macrophages. Journal of Immunology 1992, 148 (7), 2207-2216.

18. Fadok, V. A.; Henson, P. M., Apoptosis: Getting rid of the bodies. Current Biology 1998, 8 (19), R693-R695. 
19. Verhoven, B.; Schlegel, R. A.; Williamson, P., Mechanisms of phosphatidylserine exposure, a phagocyte recognition signal, on apoptotic T lymphocytes. J. Exp. Med. 1995, 182 (5), 1597-1601.

20. Schlegel, R.; Williamson, P., Phosphatidylserine, a death knell. Cell Death Differ. 2001, $8(6), 551$.

21. Daleke, D. L., Regulation of transbilayer plasma membrane phospholipid asymmetry. $J$. Lipid Res. 2003, 44 (2), 233-242.

22. Slusky, J. S.; Dunbrack Jr, R. L., Charge asymmetry in the proteins of the outer membrane. Bioinformatics 2013, 29 (17), 2122-2128.

23. Sharpe, H. J.; Stevens, T. J.; Munro, S., A comprehensive comparison of transmembrane domains reveals organelle-specific properties. Cell 2010, 142 (1), 158-169.

24. Boon, J. M.; Smith, B. D., Chemical control of phospholipid distribution across bilayer membranes. Med Res Rev 2002, 22 (3), 251-281.

25. Sharom, F. J., Flipping and flopping-lipids on the move. IUBMB Life 2011, 63 (9), 736746.

26. Pomorski, T.; Hrafnsdóttir, S.; Devaux, P. F.; Meer, G. v., Lipid distribution and transport across cellular membranes. Seminars in Cell \& Developmental Biology 2001, 12 (2), 139-148.

27. Devaux, P. F., Phospholipid flippases. FEBS Letters 1988, 234 (1), 8-12.

28. Seigneuret, M.; Devaux, P. F., ATP-dependent asymmetric distribution of spin-labeled phospholipids in the erythrocyte membrane: relation to shape changes. Proceedings of the National Academy of Sciences of the United States of America 1984, 81 (12), 3751-3755.

29. Bitbol, M.; Devaux, P. F., Measurement of outward translocation of phospholipids across human erythrocyte membrane. Proceedings of the National Academy of Sciences of the United States of America 1988, 85 (18), 6783-6787.

30. Meer, G. v., Dynamic Transbilayer Lipid Asymmetry. Cold Spring Harbor Perspectives in Biology 2011, 3 (5), a004671.

31. Iglic, A., Advances in Planar Lipid Bilayers and Liposomes. Academic Press: 2012; p 357.

32. Huang, Y.; Kim, S.-H.; Arriaga, L. R., Emulsion templated vesicles with symmetric or asymmetric membranes. Adv Colloid Interface Sci 2017, 247, 413-425.

33. Marquardt, D.; Geier, B.; Pabst, G., Asymmetric lipid membranes: towards more realistic model systems. Membranes 2015, 5 (2), 180-196.

34. Hope, M. J.; Redelmeier, T. E.; Wong, K. F.; Rodrigueza, W.; Cullis, P. R., Phospholipid asymmetry in large unilamellar vesicles induced by transmembrane $\mathrm{pH}$ gradients. Biochemistry 1989, 28 (10), 4181-4187.

35. Johnson, L. W.; Hughes, M. E.; Zilversmit, D. B., Use of phospholipid exchange protein to measure inside-outside transposition in phosphatidylcholine liposomes. Biochimica et Biophysica Acta (BBA) - Biomembranes 1975, 375 (2), 176-185.

36. Zilversmit, D. B., Lipid transfer proteins. J. Lipid Res. 1984, 25 (13), 1563-1569.

37. Low, M. G.; Zilversmit, D. B., Phosphatidylinositol distribution and translocation in sonicated vesicles. A study with exchange protein and phospholipase C. Biochimica et Biophysica Acta (BBA) - Biomembranes 1980, 596 (2), 223-234.

38. Cheng, H.-T.; London, E., Preparation and Properties of Asymmetric Large Unilamellar Vesicles: Interleaflet Coupling in Asymmetric Vesicles Is Dependent on Temperature but Not Curvature. Biophysical Journal 2011, 100 (11), 2671-2678. 
39. Lin, Q.; London, E., Preparation of Artificial Plasma Membrane Mimicking Vesicles with Lipid Asymmetry. PLOS ONE 2014, 9 (1), e87903.

40. Heberle, F. A.; Marquardt, D.; Doktorova, M.; Geier, B.; Standaert, R. F.; Heftberger, P.; Kollmitzer, B.; Nickels, J. D.; Dick, R. A.; Feigenson, G. W.; Katsaras, J.; London, E.; Pabst, G., Subnanometer Structure of an Asymmetric Model Membrane: Interleaflet Coupling Influences Domain Properties. Langmuir 2016, 32 (20), 5195-5200.

41. Hamada, T.; Miura, Y.; Komatsu, Y.; Kishimoto, Y.; Vestergaard, M. d.; Takagi, M., Construction of Asymmetric Cell-Sized Lipid Vesicles from Lipid-Coated Water-in-Oil Microdroplets. The Journal of Physical Chemistry B 2008, 112 (47), 14678-14681.

42. Richmond, D. L.; Schmid, E. M.; Martens, S.; Stachowiak, J. C.; Liska, N.; Fletcher, D. A., Forming giant vesicles with controlled membrane composition, asymmetry, and contents. Proceedings of the National Academy of Sciences of the United States of America 2011, 108 (23), 9431-9436.

43. Hu, P. C.; Li, S.; Malmstadt, N., Microfluidic Fabrication of Asymmetric Giant Lipid Vesicles. ACS Applied Materials \& Interfaces 2011, 3 (5), 1434-1440.

44. Peyret, A.; Ibarboure, E.; Le Meins, J. F.; Lecommandoux, S., Asymmetric Hybrid Polymer-Lipid Giant Vesicles as Cell Membrane Mimics. Advanced Science 2018, 5 (1), 1700453.

45. Kamiya, K.; Kawano, R.; Osaki, T.; Akiyoshi, K.; Takeuchi, S., Cell-sized asymmetric lipid vesicles facilitate the investigation of asymmetric membranes. Nature chemistry 2016, 8 (9), 881-889.

46. Visco, I.; Chiantia, S.; Schwille, P., Asymmetric supported lipid bilayer formation via methyl- $\beta$-cyclodextrin mediated lipid exchange: influence of asymmetry on lipid dynamics and phase behavior. Langmuir 2014, 30 (25), 7475-7484.

47. Li, S.; Mehta, A. K.; Sidorov, A. N.; Orlando, T. M.; Jiang, Z.; Anthony, N. R.; Lynn, D. G., Design of Asymmetric Peptide Bilayer Membranes. Journal of the American Chemical Society 2016, 138 (10), 3579-3586.

48. Lim, S. K.; Wong, A. S. W.; Hoog, H.-P. M. d.; Rangamani, P.; Parikh, A. N.; Nallani, M.; Sandin, S.; Liedberg, B., Spontaneous formation of nanometer scale tubular vesicles in aqueous mixtures of lipid and block copolymer amphiphiles. Soft Matter 2017, 13 (6), 11071115.

49. Mason, A. F.; Thordarson, P., Polymersomes with asymmetric membranes based on readily accessible di-and triblock copolymers synthesized via SET-LRP. ACS Macro Lett. 2016, $5(10), 1172-1175$.

50. Konishcheva, E. V.; Zhumaev, U. E.; Meier, W. P., PEO-b-PCL-b-PMOXA Triblock Copolymers: From Synthesis to Microscale Polymersomes with Asymmetric Membrane. Macromolecules 2017.

51. Stoenescu, R.; Meier, W., Vesicles with asymmetric membranes from amphiphilic ABC triblock copolymers. Chemical Communications 2002, (24), 3016-3017.

52. Matosevic, S.; Paegel, B. M., Layer-by-layer cell membrane assembly. Nature chemistry 2013, 5 (11), 958-963.

53. Lu, L.; Schertzer, J. W.; Chiarot, P. R., Continuous microfluidic fabrication of synthetic asymmetric vesicles. Lab on a chip 2015, 15 (17), 3591-3599.

54. Karamdad, K.; Law, R.; Seddon, J.; Brooks, N.; Ces, O., Studying the effects of asymmetry on the bending rigidity of lipid membranes formed by microfluidics. Chemical Communications 2016, 52 (30), 5277-5280. 
55. Zhao, H. Synthetic membranes in microfluidic interfaces. University of Glasgow, 2017. 56. Fernandez-Trillo, F.; Grover, L. M.; Stephenson-Brown, A.; Harrison, P.; Mendes, P. M., Vesicles in Nature and the Laboratory: Elucidation of Their Biological Properties and Synthesis of Increasingly Complex Synthetic Vesicles. Angewandte Chemie International Edition 2017, 56 (12), 3142-3160.

57. Markones, M.; Zorzin, C.; Kaiser, M.; Kalie, L.; Heerklotz, H.; Fiedler, S., Engineering asymmetric lipid vesicles: accurate and convenient control of the outer leaflet lipid composition. Langmuir 2018.

58. de Kruijff, B.; Baken, P., Rapid transbilayer movement of phospholipids induced by an asymmetrical perturbation of the bilayer. Biochimica et Biophysica Acta (BBA) - Biomembranes 1978, 507 (1), 38-47.

59. Pagano, R. E.; Martin, O. C.; Schroit, A. J.; Struck, D. K., Formation of asymmetric phospholipid membranes via spontaneous transfer of fluorescent lipid analogues between vesicle populations. Biochemistry 1981, 20 (17), 4920-4927.

60. McConnell, H. M.; Kornberg, R. D., Inside-outside transitions of phospholipids in vesicle membranes. Biochemistry 1971, 10 (7), 1111-1120.

61. Cheng, H.-T.; Megha; London, E., Preparation and Properties of Asymmetric Vesicles That Mimic Cell Membranes. J. Biol. Chem. 2009, 284 (10), 6079-6092.

62. Chiantia, S.; Schwille, P.; Klymchenko, A. S.; London, E., Asymmetric GUVs Prepared

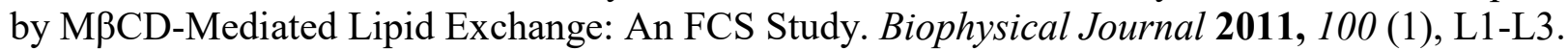

63. Anderson, T. G.; Tan, A.; Ganz, P.; Seelig, J., Calorimetric Measurement of Phospholipid Interaction with Methyl- $\beta$-Cyclodextrin. Biochemistry 2004, 43 (8), 2251-2261.

64. Hwang, W. L.; Chen, M.; Cronin, B.; Holden, M. A.; Bayley, H., Asymmetric Droplet Interface Bilayers. Journal of the American Chemical Society 2008, 130 (18), 5878-5879.

65. Pautot, S.; Frisken, B. J.; Weitz, D. A., Engineering asymmetric vesicles. Proceedings of the National Academy of Sciences 2003, 100 (19), 10718-10721.

66. Pautot, S.; Frisken, B. J.; Weitz, D. A., Production of Unilamellar Vesicles Using an Inverted Emulsion. Langmuir 2003, 19 (7), 2870-2879.

67. Xiao, Z.; Xu, M.; Li, M.; Lu, Z.; Wei, Y., Preparation of asymmetric bilayer-vesicles with inner and outer monolayers composed of different amphiphilic molecules. Supramolecular Science 1998, 5 (5), 619-622.

68. Abkarian, M.; Loiseau, E.; Massiera, G., Continuous droplet interface crossing encapsulation (cDICE) for high throughput monodisperse vesicle design. Soft Matter 2011, 7 (10), 4610-4614.

69. Claudet, C.; In, M.; Massiera, G., Method to disperse lipids as aggregates in oil for bilayers production. Eur. Phys. J. E 2016, 39 (1), 9.

70. Shah, R. K.; Shum, H. C.; Rowat, A. C.; Lee, D.; Agresti, J. J.; Utada, A. S.; Chu, L.-Y.; Kim, J.-W.; Fernandez-Nieves, A.; Martinez, C. J., Designer emulsions using microfluidics. Materials Today 2008, 11 (4), 18-27.

71. Shum, H. C.; Thiele, J.; Kim, S.-H., Microfluidic fabrication of vesicles. In Advances in transport phenomena 2011, Springer: 2014; pp 1-28.

72. Stachowiak, J. C.; Richmond, D. L.; Li, T. H.; Brochard-Wyart, F.; Fletcher, D. A., Inkjet formation of unilamellar lipid vesicles for cell-like encapsulation. Lab on a chip 2009, 9 (14), 2003-2009. 
73. Stachowiak, J. C.; Richmond, D. L.; Li, T. H.; Liu, A. P.; Parekh, S. H.; Fletcher, D. A., Unilamellar vesicle formation and encapsulation by microfluidic jetting. Proceedings of the National Academy of Sciences 2008, 105 (12), 4697-4702.

74. Sackmann, E., Supported Membranes: Scientific and Practical Applications. Science 1996, 271 (5245), 43-48.

75. Sanderson, J. M., Resolving the kinetics of lipid, protein and peptide diffusion in membranes. Molecular Membrane Biology 2012, 29 (5), 118-143.

76. Lin, W.-C.; Blanchette, C. D.; Ratto, T. V.; Longo, M. L., Lipid Asymmetry in DLPC/DSPC-Supported Lipid Bilayers: A Combined AFM and Fluorescence Microscopy Study. Biophysical Journal 2006, 90 (1), 228-237.

77. Wacklin, H. P., Composition and Asymmetry in Supported Membranes Formed by Vesicle Fusion. Langmuir 2011, 27 (12), 7698-7707.

78. Cooper, G. M., Structure of the Plasma Membrane. 2nd edition. Sunderland (MA): Sinauer Associates: 2000.

79. Kamat, N. P.; Katz, J. S.; Hammer, D. A., Engineering Polymersome Protocells. The Journal of Physical Chemistry Letters 2011, 2 (13), 1612-1623.

80. Marguet, M.; Bonduelle, C.; Lecommandoux, S., Multicompartmentalized polymeric systems: towards biomimetic cellular structure and function. Chemical Society Reviews 2012, 42 (2), 512-529.

81. Städler, B.; Price, A. D.; Chandrawati, R.; Hosta-Rigau, L.; Zelikin, A. N.; Caruso, F., Polymer hydrogel capsules: en route toward synthetic cellular systems. Nanoscale 2009, 1 (1), 68-73.

82. Discher, B. M.; Won, Y.-Y.; Ege, D. S.; Lee, J. C. M.; Bates, F. S.; Discher, D. E.; Hammer, D. A., Polymersomes: Tough Vesicles Made from Diblock Copolymers. Science 1999, 284 (5417), 1143-1146.

83. Discher, D. E.; Eisenberg, A., Polymer Vesicles. Science 2002, 297 (5583), 967-973.

84. Meins, J. F. L.; Sandre, O.; Lecommandoux, S., Recent trends in the tuning of polymersomes' membrane properties. Eur. Phys. J. E 2011, 34 (2), 14.

85. Mason, A. F.; Thordarson, P., Polymersomes as protocellular constructs. Journal of Polymer Science Part A: Polymer Chemistry 2017, 55 (23), 3817-3825.

86. Peyret, A.; Ibarboure, E.; Pippa, N.; Lecommandoux, S., Liposomes in polymersomes: Multicompartment system with temperature-triggered release. Langmuir 2017, 33 (28), 70797085.

87. Perro, A.; Nicolet, C.; Angly, J.; Lecommandoux, S.; Le Meins, J.-F.; Colin, A., Mastering a Double Emulsion in a Simple Co-Flow Microfluidic to Generate Complex Polymersomes. Langmuir 2011, 27 (14), 9034-9042.

88. Shum, H. C.; Zhao, Y.-j.; Kim, S.-H.; Weitz, D. A., Multicompartment Polymersomes from Double Emulsions. Angewandte Chemie International Edition 2011, 50 (7), 1648-1651.

89. Kim, S.-H.; Shum, H. C.; Kim, J. W.; Cho, J.-C.; Weitz, D. A., Multiple Polymersomes for Programmed Release of Multiple Components. Journal of the American Chemical Society 2011, 133 (38), 15165-15171.

90. Peters, R. J. R. W.; Marguet, M.; Marais, S.; Fraaije, M. W.; van Hest, J. C. M.; Lecommandoux, S., Cascade Reactions in Multicompartmentalized Polymersomes. Angewandte Chemie International Edition 2014, 53 (1), 146-150. 
91. Chiu, H.-C.; Lin, Y.-W.; Huang, Y.-F.; Chuang, C.-K.; Chern, C.-S., Polymer Vesicles Containing Small Vesicles within Interior Aqueous Compartments and $\mathrm{pH}$-Responsive Transmembrane Channels. Angewandte Chemie International Edition 2008, 47 (10), 1875-1878. 92. Fu, Z.; Ochsner, M. A.; Hoog, H.-P. M. d.; Tomczak, N.; Nallani, M., Multicompartmentalized polymersomes for selective encapsulation of biomacromolecules. Chemical Communications 2011, 47 (10), 2862-2864.

93. Städler, B.; Chandrawati, R.; Price, A. D.; Chong, S.-F.; Breheney, K.; Postma, A.; Connal, L. A.; Zelikin, A. N.; Caruso, F., A Microreactor with Thousands of Subcompartments: Enzyme-Loaded Liposomes within Polymer Capsules. Angewandte Chemie International Edition 2009, 48 (24), 4359-4362.

94. Trantidou, T.; Friddin, M.; Elani, Y.; Brooks, N. J.; Law, R. V.; Seddon, J. M.; Ces, O., Engineering Compartmentalized Biomimetic Micro- and Nanocontainers. ACS nano 2017, 11 (7), 6549-6565.

95. Zhang, Y.; Wu, F.; Yuan, W.; Jin, T., Polymersomes of asymmetric bilayer membrane formed by phase-guided assembly. Journal of Controlled Release 2010, 147 (3), 413-419.

96. Blanazs, A.; Massignani, M.; Battaglia, G.; Armes, S. P.; Ryan, A. J., Tailoring Macromolecular Expression at Polymersome Surfaces. Advanced Functional Materials 2009, 19 (18), 2906-2914.

97. Liu, G.; Ma, S.; Li, S.; Cheng, R.; Meng, F.; Liu, H.; Zhong, Z., The highly efficient delivery of exogenous proteins into cells mediated by biodegradable chimaeric polymersomes. Biomaterials 2010, 31 (29), 7575-7585.

98. Luo, L.; Eisenberg, A., Thermodynamic Stabilization Mechanism of Block Copolymer Vesicles. Journal of the American Chemical Society 2001, 123 (5), 1012-1013.

99. Luo, L.; Eisenberg, A., One - Step Preparation of Block Copolymer Vesicles with Preferentially Segregated Acidic and Basic Corona Chains. Angewandte Chemie International Edition 2002, 41 (6), 1001-1004.

100. Li, J.; Xiao, S.; Xu, Y.; Zuo, S.; Zha, Z.; Ke, W.; He, C.; Ge, Z., Smart Asymmetric Vesicles with Triggered Availability of Inner Cell-Penetrating Shells for Specific Intracellular Drug Delivery. ACS applied materials \& interfaces 2017, 9 (21), 17727-17735.

101. Dao, T. P. T.; Fernandes, F.; Ibarboure, E.; Ferji, K.; Prieto, M.; Sandre, O.; Meins, J.-F. L., Modulation of phase separation at the micron scale and nanoscale in giant polymer/lipid hybrid unilamellar vesicles (GHUVs). Soft Matter 2017, 13 (3), 627-637.

102. Dao, T. P. T.; Brûlet, A.; Fernandes, F.; Er-Rafik, M.; Ferji, K.; Schweins, R.; Chapel, J. P.; Fedorov, A.; Schmutz, M.; Prieto, M.; Sandre, O.; Le Meins, J. F., Mixing Block Copolymers with Phospholipids at the Nanoscale: From Hybrid Polymer/Lipid Wormlike Micelles to Vesicles Presenting Lipid Nanodomains. Langmuir 2017, 33 (7), 1705-1715.

103. Chemin, M.; Brun, P.-M.; Lecommandoux, S.; Sandre, O.; Meins, J.-F. L., Hybrid polymer/lipid vesicles: fine control of the lipid and polymer distribution in the binary membrane. Soft Matter 2012, 8 (10), 2867-2874.

104. Nam, J.; Beales, P. A.; Vanderlick, T. K., Giant Phospholipid/Block Copolymer Hybrid Vesicles: Mixing Behavior and Domain Formation. Langmuir 2011, 27 (1), 1-6.

105. Lim, S. K.; de Hoog, H.-P.; Parikh, A. N.; Nallani, M.; Liedberg, B., Hybrid, Nanoscale Phospholipid/Block Copolymer Vesicles. Polymers 2013, 5 (3), 1102-1114.

106. Le Meins, J. F.; Schatz, C.; Lecommandoux, S.; Sandre, O., Hybrid polymer/lipid vesicles: state of the art and future perspectives. Materials Today 2013, 16 (10), 397-402. 
107. Schulz, M.; Binder, W. H., Mixed Hybrid Lipid/Polymer Vesicles as a Novel Membrane Platform. Macromolecular Rapid Communications 2015, 36 (23), 2031-2041.

108. Olubummo, A.; Schulz, M.; Schöps, R.; Kressler, J.; Binder, W. H., Phase changes in mixed lipid/polymer membranes by multivalent nanoparticle recognition. Langmuir 2014, 30 (1), 259-267.

109. Su, X.; Mohamed Moinuddeen, S. K.; Mori, L.; Nallani, M., Hybrid polymersomes: facile manipulation of vesicular surfaces for enhancing cellular interaction. Journal of Materials Chemistry B 2013, 1 (42), 5751-5755.

110. Marguet, M.; Edembe, L.; Lecommandoux, S., Polymersomes in Polymersomes: Multiple Loading and Permeability Control. Angewandte Chemie International Edition 2012, 51 (5), 1173-1176.

111. Mabrouk, E.; Cuvelier, D.; Brochard-Wyart, F.; Nassoy, P.; Li, M.-H., Bursting of sensitive polymersomes induced by curling. Proceedings of the National Academy of Sciences 2009, 106 (18), 7294-7298.

112. Yu, Z.; Tantakitti, F.; Palmer, L. C.; Stupp, S. I., Asymmetric Peptide Nanoribbons. Nano Lett. 2016, 16 (11), 6967-6974.

113. Lu, L.; Doak, W. J.; Schertzer, J. W.; Chiarot, P. R., Membrane mechanical properties of synthetic asymmetric phospholipid vesicles. Soft matter 2016, 12 (36), 7521-7528.

114. Perozo, E.; Kloda, A.; Cortes, D. M.; Martinac, B., Physical principles underlying the transduction of bilayer deformation forces during mechanosensitive channel gating. Nature Structural and Molecular Biology 2002, 9 (9), 696.

115. Stoenescu, R.; Graff, A.; Meier, W., Asymmetric ABC - Triblock Copolymer Membranes Induce a Directed Insertion of Membrane Proteins. Macromolecular bioscience 2004, 4 (10), 930-935.

116. Yanagisawa, M.; Iwamoto, M.; Kato, A.; Yoshikawa, K.; Oiki, S., Oriented reconstitution of a membrane protein in a giant unilamellar vesicle: experimental verification with the potassium channel KcsA. Journal of the American Chemical Society 2011, 133 (30), 11774-11779.

117. Li, X.; Huang, J.; Holden, M. A.; Chen, M., Peptide-Mediated Membrane Transport of Macromolecular Cargo Driven by Membrane Asymmetry. Analytical chemistry 2017, 89 (22), 12369-12374. 


\section{TOC Graphic}

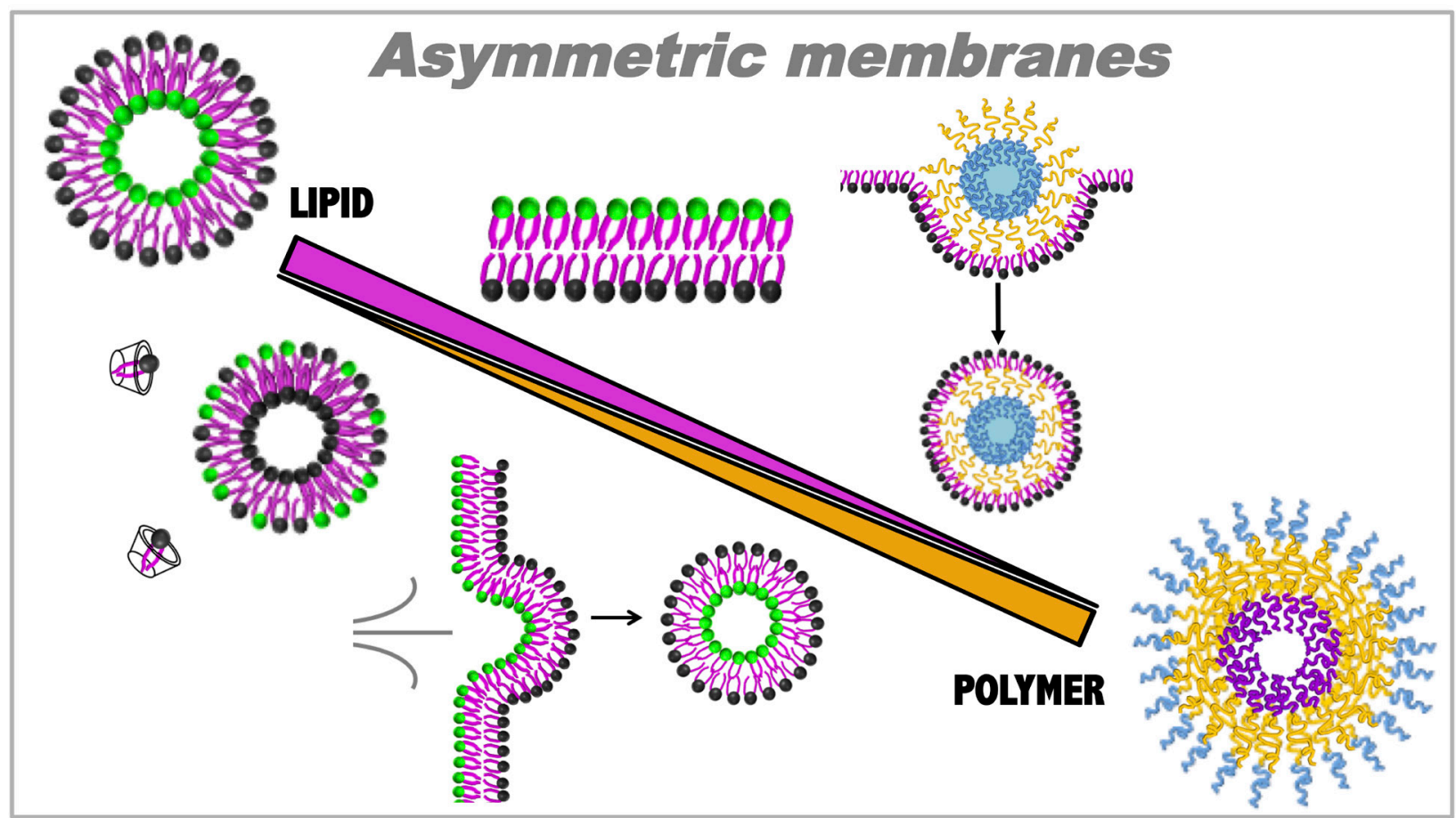




\section{Authors biographies}

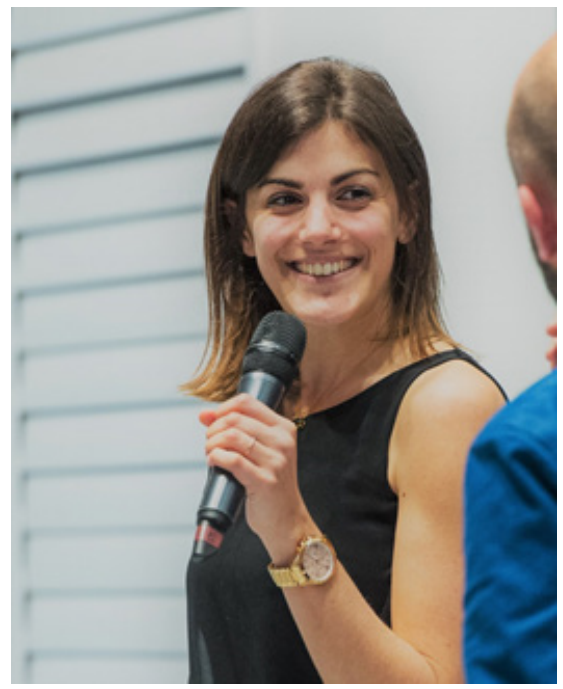

Ariane Peyret received her M. Sc. Degree in polymer nanotechnologies from the University of Toulouse (France) in 2014. In 2017, she obtained her Ph.D. Degree in Polymer Chemistry from the University of Bordeaux (France). Her PhD project was performed at the Laboratoire de Chimie des Polymères Organiques (LCPO, CNRS UMR-5629) under the supervision of Prof. Sébastien Lecommandoux and focused on synthetic biomimetic vesicles. She now works as a formulation scientist in a private company (France).

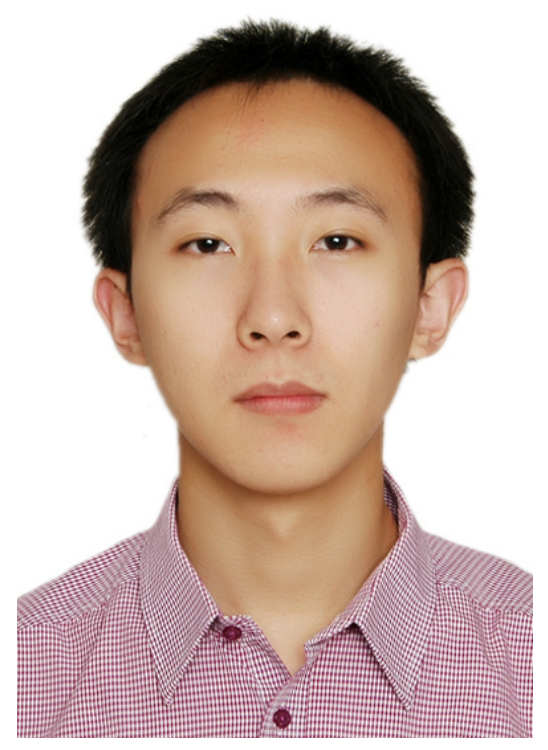

Hang Zhao is a postdoctoral research at the Laboratoire de chimie des Polymeres Organiques (LCPO-CNRS). He received his B.Sc. Degree in Chemical Engineering from Sichuan University (2012) and Ph.D. Degree in Biomedical Engineering in the University of Glasgow (2017). His current research lies at the interface of biochemistry and lipids/polymers membrane, with a focus on construction of synthetic cellular systems. 


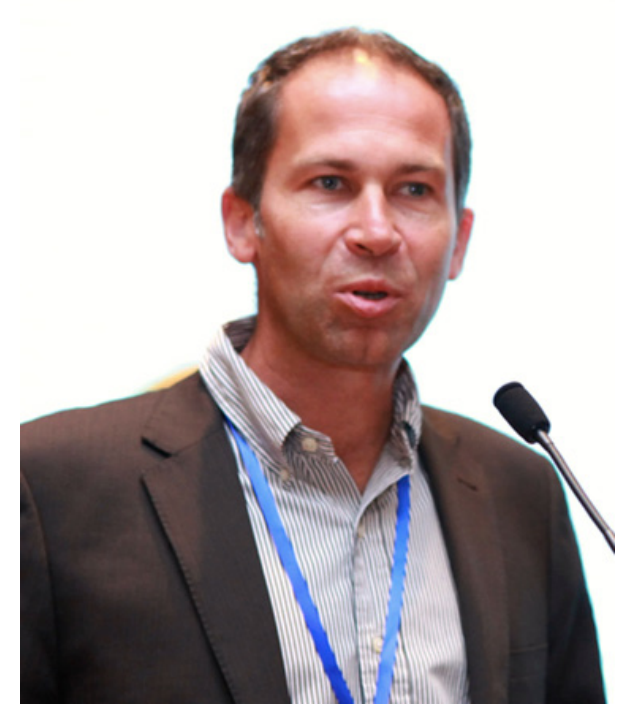

After a postdoctoral experience in Sam Stupps's group at Urbana-Champaign (USA) in 1998, Sébastien Lecommandoux joined the Univ. Bordeaux (France) as Assistant Professor and is currently Full Professor and Director of the "Laboratoire de Chimie des Polymères Organiques", leading the group "Polymer Self-Assembly and Life Sciences". His research interests include polypeptide and polysaccharide based block copolymers self-assembly, biomimetic approaches toward design of synthetic viruses and cells as well as the design of polymersomes for drugdelivery and theranostic. He published more than 180 publications in international journal, 6 book chapters and 5 patents, with about 10000 citations. He received the CNRS Bronze medal in 2004, Institut Universitaire de France (IUF) Junior Award in 2007 and became Fellow of the Royal Society of Chemistry (RSC) in 2017. He is in the Editorial Advisory Board of several international journals, including Bioconjugate Chemistry (ACS), Polymer Chemistry and Biomaterials Science (RSC) and Associate Editor for Biomacromolecules (ACS) since 2013. 